\title{
Communication skills and their association with self-reported academic performances of Nigerian pharmacy students
}

\author{
C M Ubaka, PhD; C V Ukwe, PhD
}

Department of Clinical Pharmacy and Pharmacy Management, Faculty of Pharmaceutical Sciences, University of Nigeria, Nsukka, Nigeria

Corresponding author: C M Ubaka (pharmubk@yahoo.com)

Background. Effective communication is an important attribute for practising pharmacists worldwide. However, little is known about the effects of communication skills on pharmacy students' academic performances in Nigerian pharmacy schools.

Objectives. To identify the distribution of two communication skills, i.e. assertiveness and reticence, among pharmacy students and the association of these skills with the students' academic performances.

Methods. Seven pharmacy schools were randomly sampled in this study. A validated 18-item questionnaire measuring communication constructs, assertiveness and reticence was distributed to eligible students after ethical approval had been obtained. The questionnaire adopted a 5-point Likert scale for responses. Demographic details and self-reported academic performances in the most recent pharmacy examinations were also collected. Descriptive and regression statistics were reported for the distribution of these communication skills and student factors that influence performances, respectively. Results. Pharmacy students ( $n=1550)$ were surveyed. Students were more assertive (mean 3.40) than reticent (mean 3.30) in their communication. Female students were more reticent and less assertive than male students $(p \leq 0.05)$, but age had no influence on either construct. Being highly assertive was associated with higher grade performances in the three courses examined ( $p \leq 0.027$ for each course). However, for clinical pharmacy, lower reticence scores were associated with better academic performances $(p=0.035)$. Regression analysis showed that assertive pharmacy students were less likely to report lower grades in all three courses $(p \leq 0.004)$ and reticent students were more likely to report lower grades in only clinical pharmacy $(p=0.042)$.

Conclusions. Assertive and reticent communication skills were present among Nigerian pharmacy students. Being assertive and reticent, as well as students' gender, age and marital status, were associated with the students' self-reported academic performances.

Afr J Health Professions Educ 2019;11(3):88-95. https://doi.org/10.7196/AJHPE.2019.v1 1i3.1099

In 2006, the World Health Organization (WHO), in collaboration with the International Pharmaceutical Federation (FIP), underpinned the new concept of a 7-star pharmacist. Among other attributes, it especially called for pharmacists globally to be communicators. The pharmacist is thus seen as being in 'an ideal position to provide a link between prescriber and patient and to communicate information on health and medicines to the public. ${ }^{[1]}$ Pharmacists who are skilled communicators have been reported to be more likely to have a greater influence on prescribing than those who communicate less effectively. ${ }^{[2]}$

Effective communication skills training is essential in pharmacy education and eventual pharmacy practice, especially during patient and medication counselling. These skills have been shown to improve patient outcomes and satisfaction and also to enhance pharmacists' status and self-esteem. ${ }^{[3]}$ Assertiveness is an effective communication skill important for patient safety and teamwork. ${ }^{[4]}$ This skill has been described as the direct expression of ideas and opinions, while respecting the rights of others in an atmosphere of trust. ${ }^{[4,5]}$ It is said to be the middle state between aggression and passivity and includes skills such as responding appropriately to criticism, being persistent and expressing one's opinions and feelings appropriately. ${ }^{[6]}$

The literature suggests that there are communication difficulties among pharmacists and pharmacy students. ${ }^{[7-9]}$ These difficulties could interfere with the provision of pharmaceutical care to a patient and crosscommunication with other colleagues in and outside the healthcare team. Communication difficulties have been divided into various subtypes, including apprehension, reticence and shyness, and are characterised by some form of communication problem. ${ }^{[8]}$ Communication apprehension has been conceptualised as 'an individual's level of fear or anxiety associated with either real or anticipated communication with another person or persons, ${ }^{[10]}$ while reticence, on which this study focuses, is viewed as primarily a problem of repeated ineffectiveness in communication encounters. ${ }^{[1]}$

Not much research has been done regarding communication skills ability among pharmacy students; it has focused mainly on communication apprehension. Studies in the 1980s, investigating communication apprehension and shyness among a large group of pharmacy students, reported that 1 in 5 students was highly communication apprehensive and over a third were shy. ${ }^{[8]}$ Recently, two studies conducted among Malaysian pharmacy students focused on communication apprehension, and reported the prevalence of such communication difficulty among its pharmacy students. ${ }^{[9,12]}$ The first study, a comparative survey of communication apprehension among first- and final-year students of a pharmacy school in Malaysia, reported a greater prevalence of communication apprehension among first-year students. The study also reported many cases of communication apprehension among females and younger-aged pharmacy students. ${ }^{[12]}$ The second study was conducted a year later, in 2010, among first-year pharmacy students in one school. The findings showed that communication apprehension was significantly high, but there were no differences between male and female students. One in 4 students selfreported communication apprehension..$^{[9]}$ These studies might, however, 
not reflect the views of African or specifically Nigerian students. Also, the studies did not include students in other years of pharmacy training and did not focus on possible factors that could be associated with student communication skills.

From 2019, pharmacy training in Nigerian pharmacy schools is slowly but steadily migrating to the patient-centred Doctor of Pharmacy programme, and it is important to evaluate students' communication skills status, as they will engage and communicate more with peers, instructors and patients. Such an evaluation is also important in the context of male/female inequality regarding scholarly and productivity expectations, which is believed to be common in the African setting. This inequality could interfere with communication abilities of female pharmacy students, especially with their male counterparts. There is currently no literature on communication skills or communication difficulty among pharmacy students in Africa. To the best of our knowledge, there is also no literature on the association between communication skills and academic performance among pharmacy students.

Therefore, the objectives of this study were as follows: ( $i$ ) to measure the distribution of communication skills - assertiveness and reticence - among pharmacy students; and (ii) to evaluate the association of assertiveness and reticence with academic performances of pharmacy students in selected pharmacy examinations.

\section{Methods Setting}

The Bachelor of Pharmacy degree is the minimum qualification necessary to practise pharmacy in Nigeria. Pharmacy training in Nigeria is regulated by the Pharmacists Council of Nigeria (PCN) and curricular contents and modules are similar across the same years of study in all pharmacy schools. Teaching styles might differ slightly among schools and within a school, but training schedules and a time frame are regulated by the PCN in all pharmacy schools. The Bachelor of Pharmacy programme in Nigeria comprises 5 years, including 1 year of pre-pharmacy training. During the next 4 years, often regarded as professional years, students are trained over 5 broad course areas, i.e. pharmacology, pharmaceutics, pharmacognosy, clinical pharmacy and pharmaceutical chemistry. Pharmacology, clinical pharmacy and pharmaceutics are studied during all training years from the third to the fifth year, unlike pharmacognosy and chemistry, which are not. In the former courses there is more contact and communication with instructors and preceptors. All pharmacy courses in Nigeria are offered over a 2-semester period, each covering 4.5 months of an academic year. Communication skills training is introduced in the final year of study before and during clinical rotations of the clinical pharmacy course.

\section{Design}

This multicentre study was designed as a cross-sectional survey conducted among university pharmacy students at the end of the second semester of the 2014/2015 academic session.

\section{Population and sample}

There are 19 pharmacy schools in Nigeria, of which only 12 had received full council accreditation at the time of the study. All pharmacy students from their third to fifth course year formed the study population. Only 7 councilaccredited pharmacy schools in the country were selected by a multi-stage sampling technique from 12 accredited schools, employing both cluster and random sampling methods. The country was divided into three clusters, i.e. South South-East, South-West, and North, based on regions having an accredited pharmacy school. The schools were then randomly selected 'proportionally' within each cluster to produce 7 schools from the possible 11: South South-East $(n=3 / 40)$; South-West $(n=2 / 4)$; and North $(n=2 / 3)$.

Pharmacy students from these schools who had registered for study and completed the pharmacy professional examinations the previous academic year (i.e. from the third to the fifth year) were eligible to participate and were included in the study $(n=2$ 156). First-year pharmacy students who do not take professional examinations, and second-year pharmacy students who had yet to take their professional examinations, were excluded from the survey. Verbal consent was obtained from all participating students.

\section{Survey instrument}

The questionnaire used in this study was a modification of a previous questionnaire and validated by Lee et al. ${ }^{[16]}$ to assess the effects of assertiveness and reticence on the performance of medical interns in their clerkship specialties. The original questionnaire comprised 12 items (Cronbach's alpha coefficient 0.82) and assessed students' assertiveness and communication abilities during classes. These items evaluated students' ease of public speaking, confidence, risk-taking, on-the-spot questioning and networking. ${ }^{[16]}$ It also included 6 items (Cronbach's alpha coefficient 0.74 ) that assessed reticence (shyness or discomfort) when being questioned by lecturers/instructors. ${ }^{[16]}$ Responses to these items were scored on a 5-point Likert disagree/agree scale, with a score of 5 assigned to strongly agree and 1 to strongly disagree.

Five recent pharmacy graduates of the University of Nigeria were handed the questionnaires to assess their understanding of the items and provide feedback. Some adjustments were made to 6 questionnaire items (3 each in assertiveness and reticence). The adjustments were mainly the change of resident/physician to lecturer in item 12 for assertiveness, and items 1, 5 and 6 for reticence. Other adjustments were the rewording of items 2 and 8 for assertiveness to reflect a classroom or laboratory setting. The final questionnaire comprised 18 items (12 assertiveness and 6 reticence). Students' characteristics, such as year of enrolment, age, gender and marital status, were also collected. They were requested to report their performances in percentages or letter grades as applicable in 3 preselected pharmacy examinations, i.e. pharmacology, clinical pharmacy and pharmaceutics. Permission to conduct the survey in each school was obtained from the dean or head of the faculty. Students were approached immediately after a mandatory class or laboratory session and the survey instrument was administered while they were seated in the class. Participation was voluntary and no reward was offered or penalty imposed for participation or nonparticipation, respectively.

\section{Statistical analysis}

Retrieved questionnaires were collected; all items were coded appropriately, entered into the 2015 Microsoft Excel (USA) spreadsheet and cross-checked for accuracy. Coded data were transferred into SPSS 20.0 (IBM Corp, USA). The schools of pharmacy were de-identified and recorded as A, B, C, D, E, F and G before the analysis. All questionnaire items were first reported as frequencies, percentages and means. Mean responses to the reticence and assertiveness scales were summarised as low and high for 
mean scores $\leq 3.0$ and $>3.0$, respectively. Differences in mean responses for each of the constructs by students' demographic variables were conducted by independent Student's $t$-test and analysis of variance, followed by Scheffe post hoc analyses. Students' self-reported performances were then classified as lower grades, representing self-reported scores $<70 \%$, or between grades $\mathrm{B}$ and $\mathrm{F}$ and highest grades, representing scores $\geq 70 \%$ or grade $\mathrm{A}$, respectively. This grading system is specific to universities in this country, where grade $\mathrm{A}$ is $\geq 70 \%$, B is $60-69 \%$, C is $50-59 \%$, D is $45-49 \%$, $\mathrm{E}$ is 40 - $44 \%$ and $\mathrm{F}$ is $<40 \%$. A $\chi^{2}$ analysis was done for differences in proportional data among the various student subgroups.

Multivariate logistic regression was conducted to identify factors, i.e. demographic variables and survey constructs, which influence the attainment of lower and highest grades. Odds ratios and 95\% confidence intervals were reported. An a priori significance level of $p<0.05$ was used. Cronbach's alpha was the numerical coefficient of reliability reported for the two scales tested.

\section{Ethical approval}

Ethical approval for this study was received from the University of Nigeria Teaching Hospital Research and Ethics Committee (ref. no. NREC/05/01/2008B-FWA00002458-IRB00002323), and permission was sought from each participating pharmacy school. Informed consent was obtained from each participating student before administration of the survey instrument.

\section{Results}

\section{Response rates and respondents' characteristics}

Of the 2156 students eligible for the study, 1550 from third-, fourth- and fifth-year classes of 7 schools of pharmacy took part in the survey, giving an overall response rate of $71.9 \%$. Furthermore, the individual response rates of the pharmacy schools ranged from $55 \%$ to $89 \%$.

The majority of students (84.5\%) was young, i.e. $<25$ years of age, with females representing $49.5 \%$ of all students. There were also more single students in the survey ( $n=1407 ; 90.8 \%)$. Class distribution showed a nearly equal proportion of pharmacy students for each class; third year $(n=458$; $29.5 \%)$, fourth year $(n=594 ; 38.3 \%)$ and fifth year $(n=498 ; 32.1 \%)$ (Table 1$)$.

\section{Demographic characteristics and level of assertiveness and reticence}

Pharmacy students' responses to the assertiveness scale showed a marginally high assertiveness (mean 3.40 (standard deviation (SD) 1.22)) (Table 2). Nearly half of the students disagreed with two assertiveness items: item 1 - 'If I don't know an answer to a question, I still act as though I do' (39\%); and item 2 - 'I feel comfortable when asked a question in front of the class' (48\%). Also, regarding responses to the two assertiveness items measuring confidence in communication, items 3 and 12 had mean values of 3.25 and 3.27, respectively. Cronbach's alpha of the 12 -item assertiveness scale was 0.72 , indicating good internal consistencies and reliability of the instrument in this setting.

Responses to the reticence scale (Table 3) revealed an average score of 3.03 (1.24). Interestingly, for item 6 , half $(51.5 \%)$ of the pharmacy students agreed that they were reticent, preferring not to challenge or question answers/comments from their lecturers. Cronbach's alpha for the 6 -item reticence scale was 0.66 , also indicating acceptable reliability of the instrument's construct.
Table 1. Demographic characteristics of pharmacy student participants in a non-grade indicator survey, Nigeria

\begin{tabular}{ll}
\hline Characteristics & 2156 \\
\hline Possible participants, $n$ & 1550 \\
Valid participants, $n$ & 71.9 \\
Participation rate, \% & \\
Year of study, $n$ (\%) & $458(28.4)$ \\
$\quad$ Third year (second professional) & $594(36.8)$ \\
Fourth year (third professional) & $498(30.9)$ \\
Fifth year (fourth professional) & \\
Age, years ( $n$ (\%)) & $1309(84.5)$ \\
16 - 25 & $241(15.5)$ \\
Z26 & \\
Gender, $n$ (\%) & $767(49.5)$ \\
Female & $790(50.5)$ \\
Male & \\
Marital status, $n$ (\%) & $1407(90.8)$ \\
Single & $143(8.2)$ \\
Engaged/married & \\
Schools of pharmacy (response rate), $n(\%)$ & $273(73.2)$ \\
A & $100(75.2)$ \\
B & $457(89.0)$ \\
C & $232(68.0)$ \\
D & $149(55.5)$ \\
E & $166(57.4)$ \\
F & $173(78.7)$ \\
G & \\
& \\
&
\end{tabular}

Students in their fifth year of study showed significantly lower assertiveness than those in the third and fourth years (mean 3.15 v. 3.25 v. 3.26 , respectively; $p=0.008$ ) (Table 4 ). Female students were significantly less assertive (mean 3.18 v. 3.27; $p=0.005$ ), but more reticent (mean 3.11 v. 2.99; $p=0.003$ ) than their male counterparts. Lastly, married students were found to be significantly less reticent than single students (mean 2.88 v. 3.07; $p=0.036)$ (Table 4).

\section{Influence of assertiveness and reticence on pharmacy students' performances in selected examinations}

Higher assertiveness scores were significantly associated with higher-grade performances in all three selected professional examinations $(p<0.05)$ (Table 5). Lower reticence scores were associated with higher-grade performances in clinical pharmacy $(p=0.035)$. In all the courses, there were significantly more female than male students with higher grades $(p<0.0001)$. The students who were single reported significantly more highest grades compared with students who were engaged or married $(\mathrm{p}<0.001)$. Similarly, older pharmacy students scored significantly higher grades in pharmaceutics compared with younger students $(44.4 \%$ v. 26.6 ; $p<0.0001)$.

After multivariate logistic regression analysis, pharmacy students reporting greater assertiveness were less likely to report lower grades in all three selected professional examinations ( $p \leq 0.027$, for each course). However, the odds for reporting lower grades in clinical pharmacy courses alone were significantly higher for students who were more reticent $(p=0.042)$. Male pharmacy students were more likely to report lower grades 
Table 2. Distribution of pharmacy students' responses to questions on assertiveness*

\begin{tabular}{|c|c|c|c|c|c|c|c|}
\hline Instrument domain/items & $n$ & $\begin{array}{l}\text { Strongly } \\
\text { disagree }\end{array}$ & Disagree & Undecided & Agree & $\begin{array}{l}\text { Strong } \\
\text { agree }\end{array}$ & Mean (SD) \\
\hline 1. If I don't know an answer to a question, I still act as though I do & 1501 & 17.2 & 22.1 & 22.0 & 26.2 & 12.6 & $2.95(1.3)$ \\
\hline 2. I feel comfortable when asked a question in front of the class & 1514 & 18.3 & 29.7 & 26.6 & 18.9 & 6.6 & $2.66(1.2)$ \\
\hline 3. I feel comfortable with my current communication skills & 1507 & 7.4 & 21.7 & 22.6 & 34.7 & 13.6 & $3.25(1.1)$ \\
\hline 4. I see a competitive side to pharmacy and it drives me to do well & 1498 & 4.0 & 8.1 & 18.2 & 43.3 & 26.4 & $3.82(1.3)$ \\
\hline 5. I feel confident in my potential to be a good pharmacist & 1500 & 2.5 & 3.9 & 10.4 & 37.1 & 46.0 & $4.20(0.9)$ \\
\hline 6. I have made sure that important people know who I am & 1504 & 6.8 & 15.5 & 40.3 & 23.4 & 14.0 & $3.24(1.3)$ \\
\hline 7. I am a logical and goal-directed speaker when I need to be & 1497 & 3.6 & 9.9 & 27.1 & 40.5 & 19.0 & $3.61(1.0)$ \\
\hline 8. I know how to answer a question and use it to my advantage & 1491 & 2.3 & 8.7 & 32.4 & 40.9 & 15.7 & $3.62(1.4)$ \\
\hline 9. 'Powerful' is a word I would use to describe myself & 1494 & 6.2 & 15.3 & 40.9 & 24.9 & 12.7 & $3.22(1.0)$ \\
\hline 10. I enjoy taking risks that will advance my career as a student & 1500 & 5.0 & 12.6 & 27.9 & 35.9 & 18.7 & $3.52(1.0)$ \\
\hline 11. When I know an answer to a question I am eager to respond & 1505 & 7.2 & 18.0 & 24.9 & 28.7 & 21.3 & $3.38(1.2)$ \\
\hline 12. I am confident when interacting with my lecturers and professors & 1467 & 7.5 & 17.2 & 29.9 & 32.4 & 13.0 & $3.27(1.1)$ \\
\hline
\end{tabular}

Table 3. Distribution of pharmacy students' responses to questions on reticence*

\begin{tabular}{|c|c|c|c|c|c|c|c|}
\hline Instrument domains/items & $n$ & $\begin{array}{l}\text { Strongly } \\
\text { disagree }\end{array}$ & Disagree & Undecided & Agree & $\begin{array}{l}\text { Strong } \\
\text { agree }\end{array}$ & Mean (SD) \\
\hline $\begin{array}{l}\text { 1. I don't readily respond to questions from my lecturers because I am } \\
\text { uncomfortable speaking out }\end{array}$ & 1468 & 16.3 & 26.5 & 26.1 & 21.3 & 9.8 & $2.80(1.2)$ \\
\hline $\begin{array}{l}\text { 2. I am uncomfortable responding to questions because I am not always sure } \\
\text { I'm right }\end{array}$ & 1475 & 14.1 & 27.9 & 27.8 & 22.4 & 7.9 & $2.80(1.1)$ \\
\hline $\begin{array}{l}\text { 3. I do not always ask questions, because I am afraid people will think my } \\
\text { questions are foolish }\end{array}$ & 1476 & 22.5 & 31.9 & 23.0 & 14.9 & 7.7 & $2.51(1.2)$ \\
\hline $\begin{array}{l}\text { 4. I speak and participate as much as other students, but I am still seen by } \\
\text { others as being quiet/reserved }\end{array}$ & 1468 & 12.1 & 18.9 & 27.8 & 27.2 & 14.0 & $3.11(1.2)$ \\
\hline 5. I am reserved when interacting with my lecturers & 1474 & 6.4 & 13.0 & 25.5 & 38.5 & 16.6 & $3.44(1.1)$ \\
\hline $\begin{array}{l}\text { 6. Out of respect for my lecturers, I prefer not to challenge or question their } \\
\text { answers or comments }\end{array}$ & 1470 & 7.2 & 14.9 & 26.3 & 28.0 & 23.5 & $3.46(1.2)$ \\
\hline
\end{tabular}

in two of the pharmacy courses, i.e. pharmacology and clinical pharmacy ( $p \leq 0.012$, for each course). Lastly, older students $(p=0.002)$ or those who were engaged/married $(p=0.02)$ were more likely to report lower grades in the pharmaceutics course. Regression results are displayed in Table 6.

\section{Discussion}

This cross-sectional study represents an initial attempt to investigate two communication variables, i.e. assertiveness and reticence, and their association with academic performance of pharmacy students. Results revealed that, even though both communication skills were prevalent among these students, assertiveness rather than reticence significantly influenced their academic performance.

Reticence, a communication difficulty, is prevalent among students in the schools of pharmacy surveyed. Similar studies that focused on other types of communication difficulty reported lower prevalence rates. ${ }^{[8,9,12]}$ Berger et al. ${ }^{[8]}$ reported high communication apprehension and shyness in only $19.5 \%$ and $34.4 \%$ of students, respectively, although shyness as high as $42 \%$ was reported in some schools surveyed. In studies conducted among Malaysian students, the prevalence of communication apprehension among final-year pharmacy students remained at an average of $24 \%$ (i.e. 24.6 - 23.5\%) over 3 years. ${ }^{[9,12]}$ However, a high prevalence of communication apprehension similar to figures obtained in our study was reported among Malaysian first-year pharmacy students (45.8\% in one of the studies). ${ }^{[12]}$ The high level of reticence among pharmacy students relating to their instructors in the current study should be a cause for concern for the country's pharmacy practice system, where its pharmacists are trying hard to integrate fully into patient care and counselling.

Of note are the lower levels of assertiveness and higher levels of reticence among female students than male students; yet, female students had better results in all courses evaluated. This effect of gender on communication abilities has been documented in the pharmacy and medical education literature. ${ }^{[8,12,17]}$ A study in the USA in the 1980 s reported a significantly higher communication apprehension among female pharmacy students compared with males ${ }^{[8]}$ More recently, in a study among first- and finalyear pharmacy students in Malaysia, a significantly higher percentage of females showed more communication apprehension. ${ }^{[12]}$ Studies assessing communication difficulties in medical education also associated female gender with difficulty in communication. Blanch et al., ${ }^{[17]}$ in 2008, observed 
Table 4. Summary of pharmacy students' responses to assertiveness and reticence by demographic characteristics

\begin{tabular}{|c|c|c|c|c|c|c|}
\hline Variable & $n$ & Assertiveness, mean (SD) & $p$-value & $n$ & Reticence, mean (SD) & $p$-value \\
\hline School of pharmacy* & & & $<0.0001$ & & & $<0.0001$ \\
\hline A & 215 & $3.41(0.55)$ & & 215 & $3.01(0.80)$ & \\
\hline B & 101 & $3.11(0.64)$ & & 100 & $2.69(0.76)$ & \\
\hline $\mathrm{C}$ & 477 & $2.93(0.60)$ & & 476 & $3.07(0.72)$ & \\
\hline $\mathrm{D}$ & 238 & $3.47(0.64)$ & & 233 & $3.12(0.73)$ & \\
\hline $\mathrm{E}$ & 155 & $3.29(0.49)$ & & 156 & $3.09(0.71)$ & \\
\hline $\mathrm{F}$ & 172 & $3.19(0.62)$ & & 174 & $3.17(0.75)$ & \\
\hline G & 181 & $3.49(0.63)$ & & 181 & $3.02(0.76)$ & \\
\hline Year of study ${ }^{*}$ & & & 0.008 & & & 0.682 \\
\hline Third & 454 & $3.25(0.63)$ & & 450 & $3.05(0.75)$ & \\
\hline Fourth & 591 & $3.26(0.63)$ & & 591 & $3.07(0.75)$ & \\
\hline Fifth & 494 & $3.15(0.65)$ & & 494 & $3.03(0.74)$ & \\
\hline Age, years & & & 0.456 & & & 0.914 \\
\hline$\leq 25$ & 1300 & $3.23(0.63)$ & & 1297 & $3.05(0.74)$ & \\
\hline$>25$ & 223 & $3.19(0.68)$ & & 222 & $3.04(0.80)$ & \\
\hline Gender & & & 0.005 & & & 0.003 \\
\hline Female & 766 & $3.18(0.63)$ & & 763 & $3.11(0.73)$ & \\
\hline Male & 740 & $3.27(0.64)$ & & 738 & $2.99(0.77)$ & \\
\hline Marital status & & & 0.196 & & & 0.027 \\
\hline Single & 1397 & $3.22(0.63)$ & & 1393 & $3.07(0.74)$ & \\
\hline Engaged/married & 87 & $3.31(0.75)$ & & 86 & $2.88(0.81)$ & \\
\hline
\end{tabular}

a set of medical interns during a clinical observation examination, and reported higher odds of female students being more reticent or lacking in self-confidence when dealing with real patients or communicating with their instructors. In the African context, females are perceived to be weaker and to have a minor voice and role in general adult communication. In Nigeria, for instance, it is unexpected and highly uncommon to see a female child challenge an adult in society or at home over issues that rightly favour them. This might be transferred to their educational training. A female student who is known to be vocal about issues is often labelled 'talkative', even when a male student is much more vocal. Females are expected by societal perspectives to be nice and warm and not initiate communication or negotiations as often and quickly as males, even when within their rights. ${ }^{[18]}$ This 'forced respect' for older adults might have contributed to the lower assertiveness and higher reticent behaviours among female pharmacy students in our study. There have also been reports that gender inequality from an African societal perspective has been influenced by cultural, religious and political marginalisation. ${ }^{[19]}$ Religion emphasises the role of the male as the head of the home or any gathering and in politics. For example, in Nigeria females are 'compensated' with political positions merely to fill a gender quota system. It is noteworthy that this gender-communication observation in our study was found to be different from that in another study that assessed reticence directly as a construct. The study reported that there was no significant difference in the level of assertiveness or reticence based on gender among medical interns. ${ }^{[16]}$

A cause for concern in the current study is the lowest level of assertiveness reported among final-year students compared with those in other years of study. Communication skills training is taught from the fourth year of study in most pharmacy schools and it is expected that in the final year most students should have developed assertive communication skills, even in class. These students know they are about to graduate, but would probably rather not confront their instructors even when they feel they are correct, perhaps to avoid lower marks during clerkship rounds. However, we do not know if responses among final-year students might have differed if the assertiveness items were directed towards their communication with patients and not their preceptors/instructors.

Students reporting lower assertiveness, a sign of communication difficulty, were more likely to report lower grades in all courses. Also, students reporting greater reticence were more likely to report poorer grades in clinical pharmacy courses - a result also seen with medical interns and performances in some select clerkship courses. ${ }^{[16]}$ These clinically based courses demand a high interaction time with instructors/preceptors and these students might have expressed their true state of mind of being reticent.

In pharmacy practice, reasons for pharmacists' communication difficulties with other health professionals include a struggle for power, poor communication, lack of trust and an unsatisfactory communication environment. ${ }^{[7]}$ These factors could result in a strained working relationship between key professionals and could negatively affect patient outcomes. ${ }^{[20]}$ However, the literature shows that when pharmacists make suggestions to physicians regarding important changes in a patient's drug treatment, the recommendations are usually accepted and implemented. ${ }^{[21]}$ Pharmacy students lacked confidence, as expressed by low mean values of survey items measuring confidence when communicating. To boost confidence, students and pharmacists must possess knowledge, willingness and belief to provide effective communication. ${ }^{[22]}$

Rogers and King, ${ }^{[23]}$ in a recent study, suggested three factors that are possibly responsible for impeding the development of effective 


\section{Research}

\begin{tabular}{|c|c|c|c|}
\hline Course $^{*}$ & Lower grades & Highest grades & $p$-value \\
\hline \multicolumn{4}{|l|}{ Pharmacology } \\
\hline Age, years $(n(\%))$ & & & 0.131 \\
\hline$\leq 25$ & $748(83.3)$ & $150(16.7)$ & \\
\hline$>25$ & $162(90.0)$ & $18(10.0)$ & \\
\hline Gender, $n(\%)$ & & & $<0.0001$ \\
\hline Female & $438(79.6)$ & $112(20.4)$ & \\
\hline Male & $461(89.5)$ & $54(10.5)$ & \\
\hline Marital status, $n(\%)$ & & & 0.458 \\
\hline Single & $823(84.3)$ & $153(15.7)$ & \\
\hline Engaged/married & $60(85.7)$ & $10(14.3)$ & \\
\hline Assertiveness, mean (SD) & $3.21(0.64)$ & $3.33(0.65)$ & 0.027 \\
\hline Reticence, mean (SD) & $3.04(0.77)$ & $3.07(0.71)$ & 0.654 \\
\hline \multicolumn{4}{|l|}{ Clinical pharmacy } \\
\hline Age, years $(n(\%))$ & & & 0.007 \\
\hline$\leq 25$ & $660(79.4)$ & $171(20.6)$ & \\
\hline$>25$ & $149(87.6)$ & $21(12.4)$ & \\
\hline Gender, $n(\%)$ & & & 0.001 \\
\hline Female & $399(76.7)$ & $121(23.3)$ & \\
\hline Male & $400(85.1)$ & $70(14.9)$ & \\
\hline Marital status, $n(\%)$ & & & 0.475 \\
\hline Single & $727(80.2)$ & $179(19.8)$ & \\
\hline Engaged/married & $53(81.5)$ & $12(18.5)$ & \\
\hline Assertiveness, mean (SD) & $3.18(0.63)$ & $3.38(0.74)$ & $<0.0001$ \\
\hline Reticence, mean (SD) & $3.08(0.75)$ & $2.95(0.80)$ & 0.035 \\
\hline \multicolumn{4}{|l|}{ Pharmaceutics } \\
\hline Age, years $(n(\%))$ & & & $<0.0001$ \\
\hline$\leq 25$ & $560(55.6)$ & $448(44.4)$ & \\
\hline$>25$ & $135(73.4)$ & $49(26.6)$ & \\
\hline Gender, $n(\%)$ & & & 0.036 \\
\hline Female & $338(55.6)$ & $270(44.4)$ & \\
\hline Male & $348(60.9)$ & $223(39.1)$ & \\
\hline Marital status, $n(\%)$ & & & 0.001 \\
\hline Single & $619(57.0)$ & $467(43.0)$ & \\
\hline Engaged/married & $55(76.4)$ & $17(23.6)$ & \\
\hline Assertiveness, mean (SD) & $3.12(0.65)$ & $3.42(0.58)$ & $<0.0001$ \\
\hline Reticence, mean (SD) & $3.09(0.76)$ & $3.01(0.7)$ & 0.093 \\
\hline
\end{tabular}

communication skills of pharmacy students, including a low perception of self-efficacy, poor outcome expectations during communication and communication anxiety, fear or apprehension. Instructors at a pharmacy school in the United Arab Emirates developed and tested a tool to teach assertive communication skills to pharmacy students to enable them to interact more effectively with physicians and other members of the healthcare team. ${ }^{[24]}$ The study employed simulated case scenarios of interactions between pharmacists and physicians and allowed pharmacy students to explore different communication techniques and improve their assertive communication skills. These suggested strategies can be adopted in any pharmacy school to improve communication efficiencies among its students.

Communication skills played a significant role in the academic performance of pharmacy students in this study. Being assertive was associated with better performances, which could be linked to confidence and interpersonal relationships. It is thought that students who were assertive during classes might have a better interaction with their instructors outside classes or privately. Interestingly, reticent students performed poorly in the clinical pharmacy course - a highly interactive course, especially during clinical rotations and patient case defences. Marks might not be given to more expressive students, but such confidence exhibited by assertive students might have affected subjective grading during these rotations. Lee et al. ${ }^{[16]}$ suggested that medical students who were more assertive regarding their knowledge might have been rewarded with better grades by their instructors. Importantly, the association between communication skills measured and performances of pharmacy students might not be causal, as students who scored the highest grades might in future return to being reticent over time. 


\section{Research}

\begin{tabular}{|c|c|c|c|}
\hline \multirow[b]{2}{*}{ Course $^{*}$} & \multicolumn{3}{|c|}{ Regression coefficients } \\
\hline & OR & 95\% CI & $p$-value \\
\hline \multicolumn{4}{|c|}{ Pharmacology $(n=1013)$} \\
\hline Age, years & & & 0.275 \\
\hline$\leq 25$ & 1.000 & & \\
\hline$>25$ & 1.375 & $0.776-2.436$ & \\
\hline Gender & & & $<0.0001$ \\
\hline Female & 1.000 & & \\
\hline Male & 2.121 & $1.466-3.069$ & \\
\hline Marital status & & & 0.684 \\
\hline Single & 1.000 & & \\
\hline Engaged/married & 1.164 & $0.559-2.423$ & \\
\hline Assertiveness & 0.668 & $0.507-0.881$ & 0.004 \\
\hline Reticence & 0.950 & $0.757-1.192$ & 0.657 \\
\hline \multicolumn{4}{|c|}{ Clinical pharmacy $(n=943)$} \\
\hline Age, years & & & 0.126 \\
\hline$\leq 25$ & 1.000 & & \\
\hline$>25$ & 1.504 & $0.892-2.538$ & \\
\hline Gender & & & 0.012 \\
\hline Female & 1.000 & & \\
\hline Male & 1.547 & $1.101-2.174$ & \\
\hline Marital status & & & 0.977 \\
\hline Single & 1.000 & & \\
\hline Engaged/married & 1.010 & $0.509-2.004$ & \\
\hline Assertiveness & 0.595 & $0.457-0.774$ & $<0.0001$ \\
\hline Reticence & 1.254 & $1.008-1.560$ & 0.042 \\
\hline \multicolumn{4}{|c|}{ Pharmaceutics ( $n=1$ 123) } \\
\hline Age, years & & & 0.002 \\
\hline$\leq 25$ & 1.000 & & \\
\hline$>25$ & 1.850 & $1.262-2.712$ & \\
\hline Gender & & & 0.14 \\
\hline Female & 1.000 & & \\
\hline Male & 1.204 & $0.941-1.540$ & \\
\hline Marital status & & & 0.02 \\
\hline Single & 1.000 & & \\
\hline Engaged/married & 2.002 & $1.115-3.596$ & \\
\hline Assertiveness & 0.433 & $0.349-0.537$ & $<0.0001$ \\
\hline Reticence & 1.125 & $0.953-1.327$ & 0.165 \\
\hline
\end{tabular}

\section{Study limitations and strengths}

This study had some limitations. Academic performances were self-reported and could have an element of bias. Verifying these would also have proved difficult, as participation was anonymous. Secondly, only schools with council accreditation were sampled. Therefore, pharmacy schools yet to receive accreditation might exhibit different levels of assertiveness and reticence. Lastly, the instrument used in this study was a modification of a questionnaire used in another setting and a different health profession. Therefore, further study of its validity is important to make conclusive statements on its reliability among Nigerian pharmacy students.

This study also possessed some strengths. It was a multicentre study conducted among students across three senior classes of the pharmacy school, thus providing a result that can generally be applicable to pharmacy training in Nigeria. The study instruments showed good reliability and can thus be applied to other schools of pharmacy with similar settings as the surveyed schools.

\section{Conclusions}

Six of every 10 pharmacy students in this survey were assertive, while nearly half of them expressed reticence when communicating with their instructors. Being assertive, single and of a female gender were all associated with higher performances in the selected pharmacy examinations. Findings suggest that communication skills training should be commenced early in pharmacy school and sustained throughout training. Special focus should be placed on vulnerable groups, such as female students, to further alleviate their communication difficulties. 
Declaration. This article was based on a study done by CMU in partial fulfilment of his $\mathrm{PhD}$ thesis.

Acknowledgements. The authors are grateful to all students, lecturers and staff of the participating schools of pharmacy.

Author contributions. CMU and CVU conceptualised and designed the study; CMU co-ordinated the survey data collection; CMU and CVU participated in the data analysis and manuscript organisation; and CMU and CVU wrote and approved the final and revised manuscript.

Funding. None.

\section{Conflicts of interest. None.}

1. Wiedenmayer K, Summers RS, Mackie CA, et al. Developing Pharmacy Practice: A Focus on Patient Care Geneva: World Health Organization, 2006.

2. Young SF, MacLeod AK. Influencing prescribing through effective communication skills. Am J Health Syst Pharm 2005;62(23):2528-2530. https://doi.org/10.2146/ajhp040305

3. Morrow N, Hargie O. Effective communication. In: Taylor K, Harding G, eds. Pharmacy Practice. London: Taylor 3. Morrow N, Hargie O. Effectivec
and Francis, 2005:207-228.

4. Tindall WN, Beardsley R, Kimberlin C. Assertiveness, in Communication Skills in Pharmacy Practice. Baltimore, MD: Williams and Wilkins, 2003 .

5. Berger BA. Assertiveness, in Communication Skills for Pharmacists: Building Relationships, Improving Patient Care. Washington:American Psychological Association, 2005.

6. Rantucci MJ. Human interactions and counseling skills in pharmacy. In: Rantucci MJ. Pharmacists Talking with Patients: A Guide to Patient Counseling. Baltimore, MD: Williams and Wilkins, 2007.

7. Kimberlin C. Communications. In: Werthiemer A, Smith MC, eds. Pharmacy Practice: Social and Behavioral Aspects. 3rd ed. Baltimore, MD: Williams and Wilkins, 1989.

8. Berger BA, Baldwin HJ, McCroskey JC, Richmond VP. Communication apprehension in pharmacy students: A national study. Am J Pharm Educ1983:47:95-102.
9. Sariff A, Gillani WS. Communication apprehension among Malaysian pharmacy students: A pilot study. Ind J Pharm Educ Res 2011;45(1):8-14

10. McCroskey JC An Introduction to Rhetorical Communication. 8th ed. Massachusetts. Prentice Hall, 2001:269-277.

11. Sokoloff KA, Phillips GM. A refinement of the concept 'reticence' J Commun Disord 1976;9(4):331-347.

12. Khan TM, Ejaz MA, Azmi S. Evaluation of communication apprehension among first year and final yea pharmacy undergraduates. J Clin Diagn Res 2009;3(6):1885-1890.

3. Sansgiry SS, Kawatkar AA, Duta AP, Bhosle, MJ. Predictors of academic performance at two universitie The effects of academic progression. Am J Pharm Educ 2004;68(4):103. https://doi.org/10.5688/aj6804103

14. Lobb WB, Wilkin NE, McCaffrey DJ, Wilson MC, Bentley JP. The predictive utility of nontraditional tes scores for first year pharmacy student academic performance. Am J Pharm Educ 2006;70(6):128. https://doi. org/10.5688/aj7006128

15. Ubaka CM, Sansgiry SS, Ukwe CV. Cognitive determinants of academic performance in Nigerian pharmacy schools. Am J Pharm Educ 2015;79(7):101. https://doi.org/10.5688/ajpe797101

16. Lee KB, Vaishnavi SN, Lau SKM, Andriole DA, Jeffe DB. 'Making the grade': Noncognitive predictors of medical students' clinical clerkship grades. J Natl Med Ass 2007;99(10):1138-1150.

17. Blanch DC, Hall JA, Roter DL, Frankel RM. Medical student gender and issues of confidence. Patient Educ Couns 2008; 72(3):374-381. https://doi.org/10.1016/j.pec.2008.05.021

18. Bowles HR, Babcock L, Lai L. Societal incentives for gender differences in the propensity to initiate negotiations Sometimes it does hurt to ask. Org Beh Hum Dec Proc 2007;103:84-103. https://doi.org/10.1016/j.obhdp.2006.09.00 9. Bako MJ, Syed J. Women's marginalization in Nigeria and the way forward. Hum Res Dev Int 2018;21(5):425-443. https://doi.org/10.1080/13678868.2018.1458567

20. Rubin RH, Sleath BL. Improving pharmacist-physician communication: Report of a pilot workshop. Am J Pharn Educ 1997;61:359-364.

1. Deady JE, Lepinski PW, Abramowitz PW. Measuring the ability of clinical pharmacists to affect drug therapy changes in a family practice clinic using prognostic indicators. Hosp Pharm 1991;26(2):93-97.

22. Anderson-Harper HM, Berger BA, Noel R. Pharmacists' predisposition to communicate, desire to counsel and job satisfaction. Am J Pharm Educ 1992;56(3):252-258.

23. Rogers ER, King SR. The influence of a patient-counseling course on the communication apprehension, outcome expectations, and self-efficacy of first year pharmacy students. Am J Pharm Educ 2012;76(8):152. https://doi. org/10.5688/ajpe 768152

24. Hasan S. A tool to teach communication skills to pharmacy students. Am J Pharm Educ 2008:72(3):67.

Accepted 1 July 2019 